\title{
Performance of Tween 80 as Surfactant for Chitosan Drug Delivery Film
}

\author{
Nadya Alfa Cahaya Imani ${ }^{\text {a,1,* }}$, Maharani Kusumaningrum ${ }^{a, 2}$ \\ ${ }^{a}$ Department of Chemical Engineering, Faculty of Engineering, Universitas Negeri Semarang, Kampus Sekaran, Gunung Pati, Semarang 50229, Indonesia \\ ${ }^{1}$ nadya.alfa@mail.unnes.ac.id*; ${ }^{2}$ maharanikusumaningrum@mail.unnes.ac.id \\ * corresponding author
}

ARTICLE INFO

Article history

Received December 04, 2019

Revised December 12, 2019

Accepted December 18, 2019

Keywords

Chitosan

Drug Delivery

Film

Kinetics

Surfactant

\section{ABSTRACT}

Optimization of the drug delivery system is based on the need for more efficient and effective drugs to fight disease. The addition of surfactant as an additive in the drug delivery precursor solution can affect the performance of the material, especially on the ability of drug release. In this study, Tween 80 was used as a surfactant to be mixed in a low molecular weight chitosan solution. Several variations of the Tween 80: chitosan ratios, as well as variations in acidity conditions, are used to determine the optimum conditions for drug release. Drug release profile fittings were tested on three kinetic models that were frequently used namely zero order model, Higuchi's model, and Korsmeyer-Peppa's model. The results showed that the optimum conditions for release were obtained with the use of a ratio of 7:10 with a release profile resembling Korsmeyer-Peppa's model.

This is an open access article under the CC-BY-SA license.

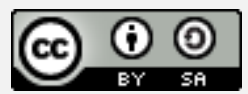

\section{Introduction}

Drug delivery is one of the medical products that began to be developed as a result of technological advances. The delivery system that can control the amount of drug that is released and the speed of release at a certain time becomes one of the main objectives of developing this advanced material in addition to the targeted release site. Until now, various materials have been studied to be used as drug vehicles, such as synthetic and natural polymers, multi-walled carbon nanotubes, silica, and various other nanomaterials [1-4]. However, because this material is intended for use in the human body, the level of toxicity, bioavailability, and biodegradability is a determining factor when choosing materials, so natural ingredients such as chitosan certainly have more advantages. Chitosan is one of the natural ingredients that have been frequently researched as a precursor drug delivery system [2].

Chitosan is a polymer that has many amine functional groups, causing it to be positively charged (poly-cation). The amine group and its nature which is easy to modify make this material to be highly explored, including in medical applications such as drug delivery [2]. In the development of chitosan as drug delivery, emulsifier agents are usually added which is useful to prevent the occurrence of aggregation which can make the drug is blocked [5]. Optimization of the use of emulsifiers or surfactants certainly needs to be done because if the amount added is not enough, then the drug cannot be released and if it is excessively added, the release rate of the drug cannot be controlled.

Tween 80 as the model surfactant is one of the highly explored nonionic surfactants. It is derived from sorbitan esters. Tween 80 is dispersible in water and known to be toxic less [6]. Among other surfactants, Tween 80 is gaining more interest due to its low cost and so it already applied in many areas including pharmaceuticals, cosmetics, and food [7,8].

Based on the facts mentioned above, this research aimed to find the optimum conditions for the addition of surfactants to the precursor of the drug delivery system solution. Furthermore, the mechanism for drug release will also be discussed by fitting experimental data on three mathematical models, namely zero order, Higuchi's model, and Korsmeyer-Peppa's model. 


\section{Research Methodology}

\subsection{Materials}

Chitosan Low Molecular Weight (Sigma grade), Tween 80, Acetic Acid (Merck), and Phosphate Buffer Saline solution pH 7.4 (made of $\mathrm{NaCl}, \mathrm{KCl}, \mathrm{Na}_{2} \mathrm{HPO}_{4}, \mathrm{KH}_{2} \mathrm{PO}_{4}$ ), Curcumin (Sigma).

\subsection{Methods}

Low molecular weight chitosan was dissolved in $0.5 \%(\mathrm{v} / \mathrm{v})$ acetic acid solution to obtain a $5 \%$ $(\mathrm{v} / \mathrm{v})$ chitosan solution. The solution was stirred for one hour using a magnetic stirrer. After that, Tween 80 with the amount mentioned in Table 1 was added to the homogeneous chitosan solution. The curcumin was also added as much as $0.03 \mathrm{mg}$ and then the solution was stirred for another hour. After a homogeneous solution was obtained, the solution was poured into a polystyrene petri dish solution with a volume of $5 \mathrm{~mL}$ for each petri. Then, the solution in the petri dish was dried at room temperature for 48 hours.

\subsection{Analysis}

In this research, Fourier Transform Infra-Red (FTIR Spectrophotometer 8201PC Shimadzu) was used to determine the chemical bonding and interactions between materials contained in the film that has been made. Calculation of drug concentrations in the release test was obtained using Spectrophotometer Vis (Genesys Vis Spectrophotometer). The release test was carried out by immersing the dried film sample (cut using a uniform mold) in the PBS solution and calculating the absorbance of the solution at a predetermined time.

Table 1. List of research variables

\begin{tabular}{cc}
\hline Weight Ratio of Tween 80:Chitosan & Code Name \\
\hline $5: 10$ & T5 \\
$6: 10$ & T6 \\
$7: 10$ & T7 \\
$10: 10$ & T10 \\
\hline
\end{tabular}

\subsection{Kinetics}

Mechanism of the drug release of the film was observed by fitting the release data profile with some very well-known models, namely zero order, Higuchi's model, and Korsmeyer-Peppa's model [9]. The equation formulas of each model are listed in Table 2.

Table 2. Kinetic model

\begin{tabular}{ccc}
\hline Model & Formula & \\
\hline Zero Order & $C_{t}=C_{0}+K_{0} t$ & $(1)$ \\
Higuchi & $Q=K_{H} t^{1 / 2}$ & (2) \\
Korsmeyer-Peppa & $\frac{M_{t}}{M_{0}}=K_{k p} t^{n}$ & \\
&
\end{tabular}

\section{Result and Discussion}

\subsection{IR analysis}

Observations on functional groups and bonds between material molecules are carried out using FTIR. This characterization needs to be done in order to prove that both chitosan and Tween 80 were present in the obtained sample. The results of the characterization can be seen in Figure 1. Sequentially on the picture are spectra from the chitosan film, Tween 80, and the mixture of the two, plus the curcumin used as a model drug. In Figure 1a, it can be seen that the chitosan film made has a characteristic vibration from its functional group, which is a large vibration region at $3100-3600 \mathrm{~cm}^{-1}$ with a peak at $3371.57 \mathrm{~cm}^{-1}$ indicating the presence of $\mathrm{OH}$ and/or NH bonds. A peak at $2877.79 \mathrm{~cm}^{-1}$ indicates the presence of alkyl CH bonds. Meanwhile peaks at $1651.07 \mathrm{~cm}^{-1}, 1558.48 \mathrm{~cm}^{-1}, 1090.14$ $\mathrm{cm}^{-1}$ indicating the presence of primary amine, secondary amine, and C-O bonds groups' vibrations [10]. 
The existence of Tween 80 in films can be confirmed using Figure 1b and Figure 1c. When compared to Figure 1a which is a spectrum of films consisting of chitosan only, there can be seen some changes that are marked by the presence of new vibrations. Peaks $(3371.3,2877.79,1558.48$, $1090 \mathrm{~cm}^{-1}$ ) of chitosan's common vibration were recorded in Figure 1c are assigned to the presence of chitosan. In addition to that, the appearance of peaks at $2924.09 \mathrm{~cm}^{-1}$ and $1735.93 \mathrm{~cm}^{-1}$ indicates Tween 80 exists in the film [11].

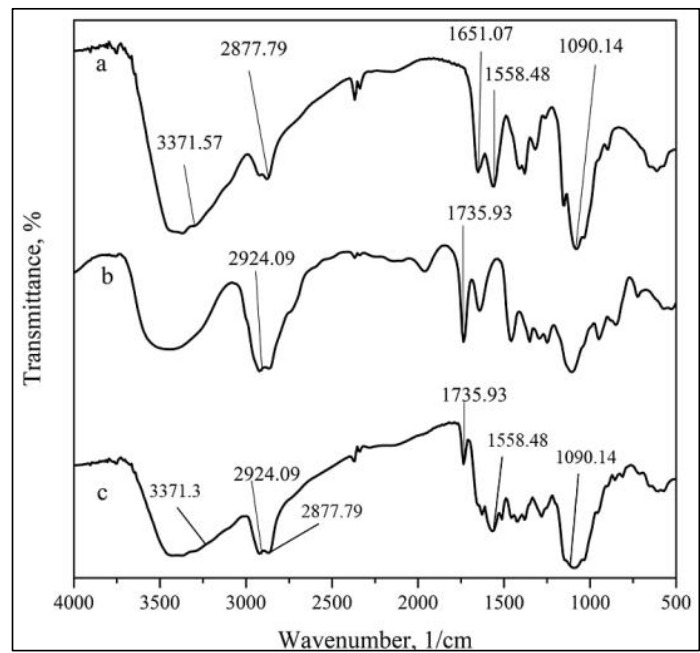

Fig. 1. FTIR result of a. Chitosan; b. Tween 80 ; c. Chitosan+Tween 80

\subsection{Release Profile: Effect of Ratios}

Surfactant which acts as an emulsifier is used to prevent the aggregation of all molecules that are used in the making process of the drug delivery system. In addition, it is especially needed in the delivery of drugs that have low solubility such as curcumin because it can increase the solubility and penetration ability of the drug to get out of the film membrane. Data on drug release from chitosan film with various amounts of Tween 80 are presented in Figure 2.

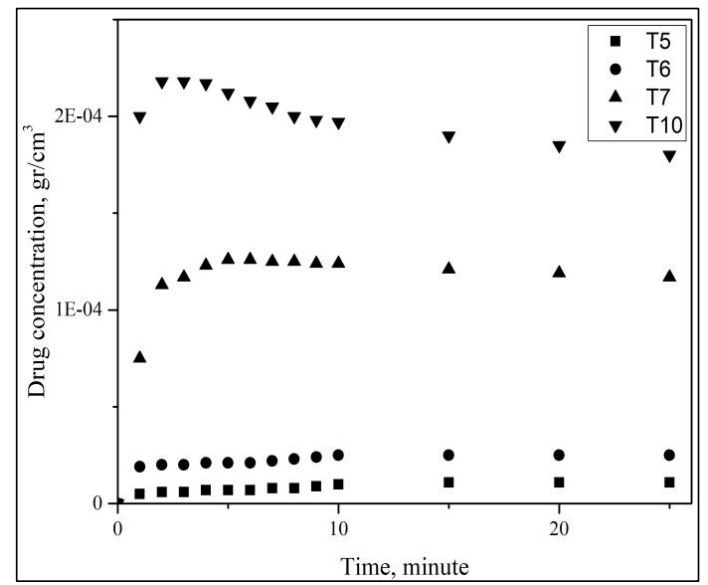

Fig. 2. Drug release profile

In Figure 2, it can be seen that with the small number of Tween 80, T5, and T6, the curcumin that comes out of the film is very small. The reason behind the phenomena is that the amount of Tween 80 with the ratio of 5:10 and 6:10 could not make the particle of both chitosan and drug to be small enough which makes the drug cannot diffuse out of the chitosan film membrane. However, as the amount of Tween 80 increases, starting at a weight ratio of 7:10 (T7) the amount of drug released from the film can increase sharply. The drug contained in each sample tested was as much as $3.52 \mathrm{x}$ $10^{-4} \mathrm{~g} / \mathrm{cm}^{3}$, so that with the addition of Tween 80 at a ratio of $10: 10$ (T10) actually only $58 \%$ of the entire drug contained in the film. From the data shown in Figure 2, it can be concluded that the increase in the amount of Tween 80 added will affect the increase in the amount of drug that can be released from the film. However, the increase in the number of Tween 80 added is stopped with T10 due to the 
more Tween 80 added will tend to result in an initial burst release. Increasing the possibility of the initial burst release can be observed by comparing T7 and T10, wherewith T7, the maximum concentration of the drug that can be released, as much as $1.245 \times 10^{-4} \mathrm{gr} / \mathrm{cm}^{3}$ is obtained at the fifth minute, whereas in the case of T10, the maximum concentration of $2.068 \times 10^{-4} \mathrm{~g} / \mathrm{cm}^{3}$ of drug can be obtained at the third minute. The increase in drug concentration that can be released from the film and the initial burst release due to the addition of the number of Tween 80 can occur because Tween 80 which is an emulsifier makes the particle size of the drug smaller (not in the form of colloids) and better dispersed in the matrix of the film so that the drug is easier to penetrate and exit the film. In addition, Tween 80 also can prevent chitosan to make an aggregate or bigger molecule size which can lead to more amount of blockage for the release of the drug.

From this study, sample T7 was chosen to be the most optimum amount of ratio because with this amount, the drug could be released in large quantities and initial burst release did not occur too fast. Also mentioned to maintain the addition of Tween 80 at the optimum amount because the addition of Tween 80 in large quantities will reduce the stability of the drug and reduce the storage time of the system.

\subsection{Drug Release Kinetics}

Fitting data on the zero-order model, Higuchi, Korsmeyer-Peppa can be seen in Figures 4, 5, 6, consecutively and the results of the calculation of the parameters of each model can be seen in Table 3. Fitting is done on sample T7 which is the sample with the best results from previous observations. From the calculation results, it is obtained that the sum of square errors (SSE) in fittings using the Korsmeyer-Peppa model is the smallest, so it can be concluded that the model is the most suitable to explain the kinetics of the release of curcumin drug from the chitosan film that has been added by Tween 80. The constant obtained from the calculation shows the release exponent value (n) is less than 0.45, which means the mechanism of drug release follows the Fickian diffusion mechanism [9].

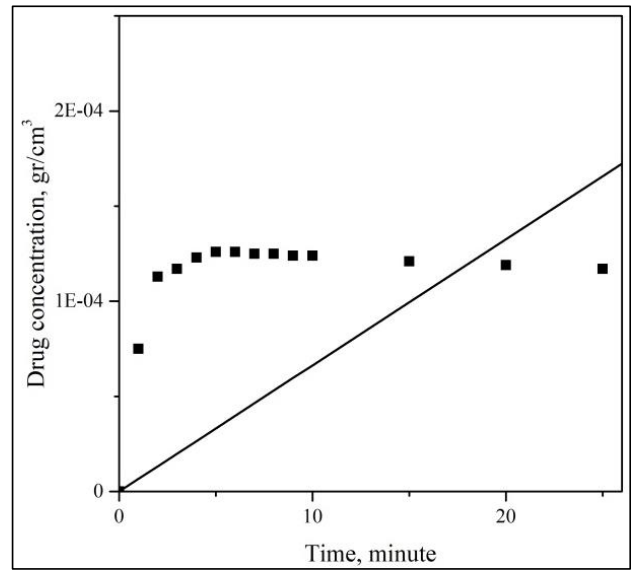

Fig. 3. Zero order release kinetic

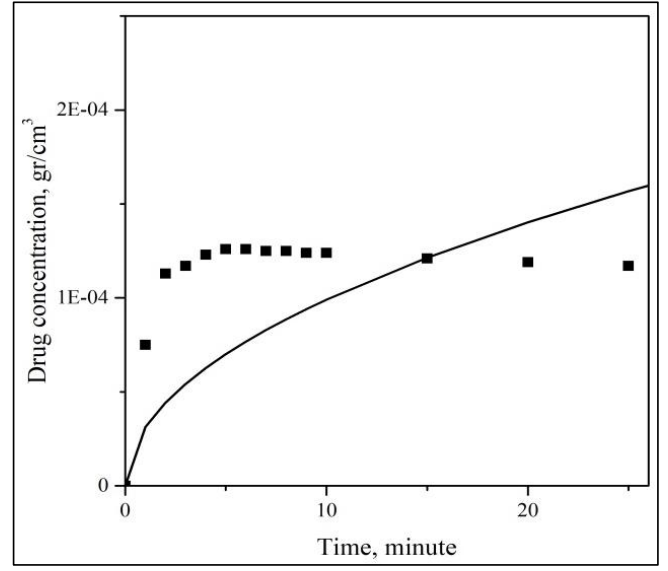

Fig. 4. Higuchi's model release kinetic

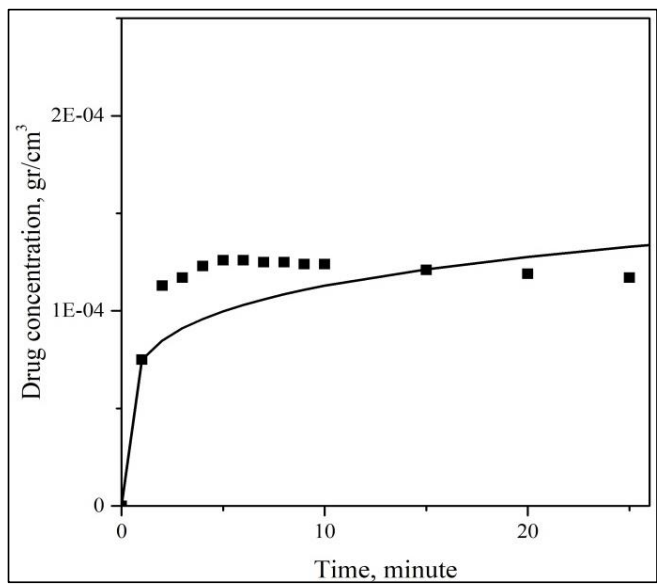

Fig. 5. Korsmeyer-Peppa's model release kinetic 
Table 3. Parameter value of each model

\begin{tabular}{ccc}
\hline Model & Parameter & SSE \\
\hline Zero order & $\mathrm{K} 0=6.63 \times 10^{-6}$ & $7.12 \times 10^{-8}$ \\
Higuchi & $\mathrm{KH}=3.13 \times 10^{-5}$ & $2.64 \times 10^{-8}$ \\
Korsmeyer-Peppa & $\mathrm{Kkp}=0.599$ & $4.68 \times 10^{-9}$ \\
& $\mathrm{n}=0.178$ & \\
\hline
\end{tabular}

\section{Conclusion}

Chitosan film with the addition of Tween 80 was successfully made to be used as a drug delivery system. The ratio of Tween 80:chitosan as much as 7:10 gave the best performance. The release mechanism from the film was best explained by Korsmeyer-Peppa's release model.

\section{Acknowledgment}

The authors would like to humbly thanks Amilia for the technical support.

\section{References}

[1] E. W. Neuse, "Synthetic polymers as drug-delivery vehicles in medicine," Met. Based. Drugs, vol. 2008, pp. 1-19, 2008.

[2] A. Bernkop-Schnürch and S. Dünnhaupt, "Chitosan-based drug delivery systems," Eur. J. Pharm. Biopharm., vol. 81, no. 3, pp. 463-469, 2012.

[3] B. Dineshkumar, K. Krishnakunar, A. R. Bhatt, D. Paul, J. Cherian, A. John, and S. Suresh,”Single-walled and multi-walled carbon nanotubes based drug delivery system: Cancer therapy: A review," Indian J. Cancer, vol 52, pp. 262-264, 2015.

[4] M. Vallet-Regí, M. Colilla, I. Izquierdo-Barba, and M. Manzano, "Mesoporous silica nanoparticles for drug delivery: Current insights," Molecules, vol. 23, no. 1, pp. 1-19, 2018.

[5] P. Kaur, T. Garg, G. Rath, R. S. R. Murthy, and A. K. Goyal, "Surfactant-based drug delivery systems for treating drug-resistant lung cancer," Drug Deliv., vol. 23, no. 3, pp. 727-738, 2016.

[6] M. Cheng et al., "Advantages and challenges of Tween 80 surfactant-enhanced technologies for the remediation of soils contaminated with hydrophobic organic compounds," Chem. Eng. J., vol. 314, pp. 98-113, 2017.

[7] H. Zhang, M. Yao, R. A. Morrison, and S. Chong, "Commonly used surfactant, Tween 80, improves absorption of P-glycoprotein substrate, digoxin, in rats," Arch. Pharm. Res., vol. 26, no. 9, pp. 768-772, 2003.

[8] S. S. Sagiri, B. Behera, T. Sudheep, and K. Pal, "Effect of composition on the properties of tween-80span-80-based organogels," Des. Monomers Polym., vol. 15, no. 3, pp. 253-273, 2012.

[9] R. Gouda, H. Baishya, and Z. Qing, "Application of Mathematical Models in Drug Release Kinetics of Carbidopa and Levodopa ER Tablets,” J. Dev. Drugs, vol. 06, no. 02, pp. 1-8, 2017.

[10] I. F. M. Rumengan, E. Suryanto, R. Modaso, S. Wullur, T. E. Tallei, and D. Limbong, "Structural Characteristics of Chitin and Chitosan Isolated from the Biomass of Cultivated Rotifer, Brachionus rotundiformis," Int. J. Fish. Aquat. Sci., vol. 3, no. 1, pp. 12-18, 2014.

[11] S. S. Sagiri, B. Behera, T. Sudheep, and K. Pal, "Effect of composition on the properties of tween-80span-80-based organogels,” Des. Monomers Polym., vol. 15, no. 3, pp. 253-273, 2012. 